\title{
Abordagem crítica sobre os direitos humanos e a proteção das pessoas portadoras de necessidades especiais
}

\author{
Critical approach on human rights \\ and the protection of persons \\ special needs carrier
}

Lucas Daniel Ferreira de Souza ${ }^{1}$

Rodrigo de Oliveira Marques ${ }^{2}$

\section{RESUMO}

O presente artigo procura elucidar alguns aspectos relativos aos direitos humanos, visando a proteção da pessoa portadora de necessidades especiais. Tal procedimento vem desenvolvendo-se ao longo dos anos, sendo que com o texto constitucional de 1988 o tema ganhou maior destaque, recebendo o tratamento devido. Nossa Carta Magna disponibilizou para a sociedade mecanismos de defesa aos direitos constitucionalmente consagrados, garantindo efetividade ao texto constitucional, e também, atuando de forma a efetivar o princípio da igualdade, o direito à dignidade e os aos direitos humanos. A metodologia desenvolvida ao longo do presente artigo, pautou-se pelo método dialético, com o estudo de textos, tendo como base uma revisão bibliográfica criteriosa, limitandose a análise de livros, artigos, teses, dissertações, revistas e jornais. Dessa forma, o caminho traçado pelo artigo partiu de uma abordagem bibliográfica inicial, com formulação da problemática, procura de fontes de pesquisa, análise do material selecionado, sistematização e acareação do tema com outras fontes bibliográficas. Portanto, o objetivo deste artigo é demonstrar que os estudos sobre as diversas formas de deficiência consolidaram o modelo social das pessoas portadoras de necessidades especiais como pessoas em desvantagem social, tal como adotado pela Convenção sobre os Direitos das Pessoas com Deficiência da Organização das Nações Unidas.

\footnotetext{
${ }_{1}^{1}$ Advogado e consultor jurídico. Mestrando em Teoria do Direito e do Estado pelo UNIVEM - Centro Universitário Eurípides de Marília, sendo bolsista CAPES/PROSUP - Coordenação de Aperfeiçoamento de Pessoal de Nível Superior. Especialista em Direito Penal e Processo Penal pela Faculdade de Direito Damásio de Jesus - FDDJ. Bacharel em Direito pelo UNIVEM - Centro Universitário Eurípides de Marília. Pesquisador do grupo de pesquisa "A Intervenção do Poder Público na Vida da Pessoa", cadastrado no diretório de grupos de pesquisa do CNPQ. Possui diversos artigos publicados em periódicos qualificados, livros e anais de eventos na área do Direito.

2 Advogado e pesquisador. Mestrando em Teoria do Direito e do Estado pelo UNIVEM - Centro Universitário Eurípides de Marília. Possui Pós-graduação Lato Sensu em Formação de Professores para o Ensino Superior pela UNIP Universidade Paulista. Possui graduação em Direito pelo Centro Universitário Toledo.
} 


\title{
PALAVRAS-CHAVE
}

Direitos humanos; princípio da igualdade; proteção; necessidades especiais.

\begin{abstract}
This article seeks to elucidate some aspects related to human rights, in order to protect the person with special needs. This procedure has been developing up over the years, and with the Constitution of 1988, the issue gained greater prominence, receiving proper treatment. Our Constitution has provided to society defense mechanisms to constitutionally enshrined rights, ensuring effectiveness in the Constitution, and also acting to give effect to the principle of equality, the right to dignity and human rights. The methodology developed throughout this article, was marked by the dialectical method to the study of texts, based on a thorough literature review, limited to analysis of books, articles, theses, dissertations, magazines and newspapers. Thus, the path traced by the paper, there is an initial bibliographic approach, formulation of the problem, demand for research sources, analysis of the selected material, systematization and theme of confrontation with other literature sources. Therefore, the purpose of this article is to demonstrate that studies on the various forms of disability consolidated the social model of people with special needs such as the socially disadvantaged, as adopted by the Convention on the Rights of Persons with Disabilities of the United Nation.
\end{abstract}

\section{KEYWORDS}

Human rights; principle of equality; protection; special needs.

\section{INTRODUÇÃO}

Destacar entre as narrativas que abordam a questão da desigualdade que se expressa no corpo, os estudos sobre deficiência foram os que surgiram recentemente no campo das ciências sociais e humanas, cujos teóricos do modelo social da deficiência provocaram uma redefinição do significado de habitar um corpo que havia sido considerado, por muito tempo, anormal. (DINIZ, 2007, p. 09).

Neste quesito, a normalidade, era entendida ora como uma expectativa biomédica de padrão de funcionamento da espécie, ora como um preceito moral de produtividade e adequação às normas sociais, na qual foi desafiada pela compreensão de que deficiência não é apenas um conceito biomédico, mas a opressão pelo corpo com variações de funcionamento.

Assim, pode-se traduzir deficiência como a opressão ao corpo com impedimentos: o conceito de corpo deficiente ou pessoa portadora de necessidades especiais devem ser entendidos em termos políticos e não mais estritamente biomédicos.

Juridicamente, a Convenção sobre os Direitos das Pessoas com Deficiência da Organização das Nações Unidas menciona a participação como parâmetro para a formulação de políticas e ações direcionadas a essa população, definindo as pessoas portadoras de necessidades especiais como "aquelas que têm impedimentos de natureza física, intelectual ou sensorial, os quais, em interação com diversas barreiras, podem obstruir sua participação plena e efetiva na sociedade com as demais pessoas" (ONU, 
2006), postula em seu artigo $1^{\circ}$. "Deficiência não é apenas o que o olhar médico descreve, mas principalmente a restrição à participação plena provocada pelas barreiras sociais".

O Brasil ratificou a Convenção sobre os Direitos das Pessoas com Deficiência em 2008, significando que um novo conceito de deficiência deve nortear as ações do Estado para a garantia de justiça a essa população. Segundo dados do Censo 2000, 14,5\% dos brasileiros apresentam impedimentos corporais como deficiência. (IBGE, 2015).

Os critérios utilizados pelo Censo 2000 para recuperar a magnitude da população com impedimentos corporais no país foram marcadamente biomédicos, tais como a gradação de dificuldades para enxergar, ouvir ou se locomover. Isso se deve não apenas ao modelo biomédico vigente na elaboração e gestão das políticas públicas para essa população no Brasil, mas principalmente à dificuldade de mensuração de o que vem a ser restrição de participação pela interação do corpo com o ambiente social.

A Convenção sobre os Direitos das Pessoas com Deficiência não ignora as especificidades corporais, por isso menciona "impedimentos de natureza física, intelectual ou sensorial" (ONU, 2006). É da interação entre o corpo com impedimentos e as barreiras sociais que se restringe a participação plena e efetiva das pessoas.

O conceito de deficiência, segundo a Convenção, não deve ignorar os impedimentos e suas expressões, mas não se resume a sua catalogação. Essa redefinição da deficiência como uma combinação entre uma matriz biomédica, que cataloga os impedimentos corporais, e uma matriz de direitos humanos, que denuncia a opressão, não foi uma criação solitária da Organização das Nações Unidas. Durante mais de quatro décadas, o chamado modelo social da deficiência provocou o debate político e acadêmico internacional sobre a insuficiência do conceito biomédico de deficiência para a promoção da igualdade entre deficientes e não deficientes. (BARNES; OLIVER; BARTON, 2002, p. 04).

Além do mais, os impedimentos são significados como desvantagens naturais por ambientes sociais restritivos à participação plena, o que historicamente traduziu os impedimentos corporais como azar ou tragédia pessoal (BARNES; OLIVER; BARTON, 2002, p. 06). Se, no século XIX, o discurso biomédico representou uma redenção ao corpo com impedimentos diante da narrativa religiosa do pecado ou da ira divina, atualmente, é a autoridade biomédica que se vê contestada pelo modelo social da deficiência. (FOUCAULT, 2004, p. 18).

\section{BREVES CONSIDERAÇÕES A RESPEITO DA GÊNESE DO MODELO SOCIAL SOBRE A DEFICIÊNCIA FÍSICA}

Ao atentarmos aproximar a deficiência da cultura dos direitos humanos, cabe ressaltar que esta foi promulgada na Inglaterra nos anos 1970. (SHAKESPEARE, 2006). A primeira geração de teóricos do modelo social da deficiência tinha forte inspiração no materialismo histórico e buscava explicar a opressão por meio dos valores centrais do capitalismo, tais como as ideias de corpos produtivos e funcionais (DINIZ, 2007, p. 23). Os corpos com impedimentos seriam inúteis à lógica produtiva em uma estrutura econômica pouco sensível à diversidade.

A crítica, por sua vez, remonta à medicalização do corpo deficiente sugerindo a insuficiência do discurso biomédico para a avaliação das restrições de participação impostas por ambientes sociais com barreiras. Por isso, para a Convenção sobre os Direitos das Pessoas com Deficiência da Organização das Nações Unidas, prevê que a 
desvantagem não é inerente aos contornos do corpo, mas resultado de valores, atitudes e práticas que discriminam o corpo com impedimentos. (DINIZ, 2007, p. 21).

Desde tempos imemoriais, a deficiência já foi tida como um drama pessoal ou familiar, com explicações religiosas que a aproximaram ora do infortúnio, ora da benção divina em quase todas as sociedades. A contestação da narrativa mística e religiosa pela narrativa biomédica foi recebida como um passo importante para a garantia da igualdade. (BARNES; OLIVER; BARTON, 2002, p. 23).

Na Idade Média, a sociedade, dominada pela religião e pelo divino, considerava que a deficiência decorria da intervenção de forças demoníacas e, nesse sentido, "muitos seres humanos física e mentalmente diferentes, e por isso associados à imagem do diabo e a atos de feitiçaria e bruxaria foram vítimas de perseguições, julgamentos e execuções" (CORREIA, 1997, p. 13). Na verdade, "a religião, com toda a sua força cultural, ao colocar o homem como 'imagem e semelhança de Deus', ser perfeito, inculcava a ideia da condição humana como incluindo perfeição física e mental”. (MAZZOTTA, 1986, 16)

Contudo, os tempos medievais viram surgir, contudo, as primeiras atitudes de caridade para com a deficiência, a piedade de alguns nobres e algumas ordens religiosas estiveram na base da fundação de hospícios e de albergues que acolheram deficientes e marginalizados.

No entanto, perdurou ao longo dos tempos e, em simultâneo com esta atitude piedosa, a ideia de que os deficientes representavam uma ameaça para pessoas e bens. A sua reclusão, que se processou em condições de profunda degradação, abandono e miséria, foi vista, por conseguinte, como necessária à segurança da sociedade.

Nos séculos XVII e XVIII, a mendicidade proliferava em todas as grandes cidades europeias. Só em Paris, durante a Guerra dos Trinta Anos, havia mais de 100.000 mendigos. Como forma de atrair a caridade, compravam-se nos asilos, crianças deficientes de tenra idade, que eram barbaramente mutiladas e abandonadas à sua sorte quando, com o avançar da idade, deixavam de ter utilidade. Relativamente aos deficientes mentais, o abandono era total.

Ao longo do século XIX e da primeira metade do século XX, os deficientes foram, assim, inseridos em instituições de caridade marcadamente assistencialista. O clima social era propício à criação de instituições cada vez maiores, construídas longe das povoações, onde as pessoas deficientes, afastadas da família e dos vizinhos, permaneciam incomunicáveis e privadas de liberdade.

As concepções pós-renascentistas que vieram dar fundamento à Escola Nova, as transformações sociais que começaram a verificar-se, na Europa, a consciência de que deficiência mental e doença mental não podem ser confundidas, o que só viria a acontecer a partir dos estudos de Esquirol, em 1818, foram marcos relevantes para a educação das pessoas portadoras de necessidades especiais. As causas divinas ou demoníacas que empenharam sacerdotes, feiticeiros e exorcistas cederam, assim, lugar a causas do fórum biológico, sociológico ou psicológico, da competência de médicos e, mais tarde, de psicólogos e de educadores.

A institucionalização teve, pois, numa fase inicial, um caráter assistencial. A preocupação com a educação surgiu mais tarde, pela mão de reformadores sociais, de clérigos e de médicos, com a contribuição de associações profissionais, então constituídas e com o desenvolvimento científico e técnico que se foi verificando, de que os testes psicométricos de Binet e Simon, cuja escala métrica da inteligência permitia avaliar os alunos que iam para escolas especiais, surgindo instituições para surdos, anos mais tarde 
para cegos e definitivamente para todos os portadores de necessidades especiais, sejam elas físicas ou intelectuais.

Ao referirmos através de expressões utilizadas no âmbito da educação de pessoas portadoras de necessidades especiais, tais como; "Pedagogia dos Anormais", "Pedagogia Teratológica", Pedagogia Curativa ou Terapêutica", "Pedagogia da Assistência Social", "Pedagogia Emendativa", que se mantiveram até ao final do século XIX. (MAZZOTTA, 1986, p. 54).

As causas dos impedimentos não estariam mais no pecado, na culpa ou no azar, mas na genética, na embriologia, nas doenças degenerativas, nos acidentes de trânsito ou no envelhecimento. A entrada do olhar médico marcou a dicotomia entre normal e patológico no campo da deficiência, pois o corpo com impedimentos somente se delineia quando contrastado com uma representação do corpo sem deficiência. $\mathrm{O}$ desafio, agora, está em recusar a descrição de um corpo com impedimentos como anormal. A anormalidade é um julgamento estético e, portanto, um valor moral sobre os estilos de vida, não o resultado de um catálogo universal e absoluto sobre os corpos com impedimentos. (DINIZ, 2007, p. 23).

Outras abordagens passaram a compor o campo dos estudos sobre deficiência, mas o modelo social se manteve hegemônico. Diferentemente da matriz do materialismo histórico dos teóricos da primeira geração, abordagens feministas e culturalistas ganharam espaço nos debates, ampliando as narrativas sobre os sentidos da deficiência em culturas da normalidade. (CORKER; SHAKESPEARE, 2002, p. 10).

Foi assim que, os impedimentos passaram a ser descritos como atributos corporais neutros, assim como as narrativas de gênero e antirracistas; e, de outro lado, a deficiência passou a resumir a opressão e a discriminação sofrida pelas pessoas com impedimentos em ambientes com barreiras. $\mathrm{O}$ modelo social da deficiência, ao resistir à redução da deficiência aos impedimentos, ofereceu novos instrumentos para a transformação social e a garantia de direitos. Não era a natureza quem oprimia, mas a cultura da normalidade, que descrevia alguns corpos como indesejáveis.

Sendo assim, a deficiência não é matéria de vida privada ou de cuidados familiares, mas uma questão de justiça (NUSSBAUM, 2007, p. 35). Essa passagem simbólica da casa para a rua abalou vários pressupostos biomédicos sobre a deficiência. Afirmou-se, que deficiência não é anormalidade, não se resumindo ao estigma ou à vergonha pela diferença. A crítica ao modelo biomédico não significa ignorar o quanto os avanços nessa área garantem bem-estar às pessoas.

As pessoas com impedimentos corporais sentem dor, adoecem, e algumas necessitam de cuidados permanentes (KITTAY, 1998, p. 09). Entretanto, os bens e serviços biomédicos são respostas às necessidades de saúde, portanto, ditos como direitos universais. Diferentemente das pessoas não deficientes, os impedimentos se constituem em estilos de vida para quem os experimentam. Por isso, há teóricos do modelo social que exploram a ideia da deficiência como identidade ou comunidade, tal como as identidades culturais. (LANE, 1997, p. 160).

Com o modelo social, a deficiência passou a ser compreendida como uma experiência de desigualdade compartilhada por pessoas com diferentes tipos de impedimentos: não são cegos, surdos ou lesados medulares em suas particularidades corporais, mas pessoas com impedimentos, discriminadas e oprimidas pela cultura da normalidade. Assim como há uma diversidade de contornos para os corpos, há uma multiplicidade de formas de habitar um corpo com impedimentos. 
Foi através dessa aproximação dos estudos sobre deficiência dos estudos culturalistas que o conceito de opressão ganhou legitimidade argumentativa: a despeito das diferenças ontológicas impostas por cada impedimento de natureza física, intelectual ou sensorial, a experiência do corpo com impedimentos é discriminada pela cultura da normalidade. $\mathrm{O}$ dualismo do normal e do patológico, representado pela oposição entre o corpo sem e com impedimentos, permitiu a consolidação do combate à discriminação como objeto de intervenção política, tal como previsto pela Convenção sobre os Direitos das Pessoas com Deficiência (ONU, 2006).

Além das formas tradicionais de discriminação, o conceito de discriminação presente na Convenção inclui a recusa de adaptação razoável, o que demonstra o reconhecimento das barreiras ambientais como uma causa evitável das desigualdades presenciadas pelas pessoas portadoras de necessidades especiais.

\section{DA SEGREGAÇÃO AO PROCESSO DE INCLUSÃO: LUTANDO PELA IGUALDADE}

A inclusão social dessas pessoas não subverteria a ordem social, pois, no caso deles, o simulacro da normalidade era eficiente para demonstrar o sucesso da inclusão. Ainda hoje, os sinais de trânsito ou as representações públicas da deficiência indicam um cadeirante como ícone.

A metonímia da deficiência pelo cadeirante não deve ser subestimada em uma cultura da normalidade repleta de barreiras à participação social de pessoas com outros impedimentos, para quem tais barreiras não são apenas físicas, mas da ordem simbólica ou comportamental.

A deficiência era, para os egípcios, indiciadora e portadora de benesses e, por isso, divinizava-se. Para os gregos e para os romanos pressagiava males futuros, os quais se afastavam, abandonando ou atirando da Rocha Tarpeia, as crianças deficientes.

A política global consiste agora em separar e isolar estas crianças do grupo principal e maioritário da sociedade. Há uma necessidade, óbvia e compreensível, de evidenciar empenho na resolução do problema: começam a surgir instituições especiais, asilos, em que são colocadas muitas crianças rotuladas e segregadas em função da sua deficiência. (CORREIA, 1997, p. 13).

No entanto, apesar da crescente preocupação com a educação destes alunos, cuja intervenção decorria de um diagnóstico médico-psico-pedagógico, o processo de colocálos numa escola de ensino especial ou numa classe especial não deixava de ser um processo segregativo.

A consciencialização, por parte da sociedade, da desumanização, da fraca qualidade de atendimento nas instituições e do seu custo elevado, das longas listas de espera, das investigações sobre as atitudes negativas da sociedade para com os marginalizados e dos avanços científicos de algumas ciências, permitiu perspectivar, do ponto de vista educativo e social, a integração das crianças e dos jovens portadores de necessidades especiais (CONDE, 2002, p. 87), à qual estava subjacente o direito à educação, à igualdade de oportunidades e ao de participar na sociedade.

Para tal, defendia-se um atendimento educativo diferenciado e individualizado, de forma a que cada aluno pudesse atingir metas semelhantes, o que implicava a necessidade de adequar métodos de ensino, meios pedagógicos, currículos, recursos humanos e materiais, bem como os espaços educativos, tendo em conta que a intervenção junto 
destes alunos, respeitando a sua individualidade, deveria ser tão precoce quanto possível e envolver a participação das famílias.

As questões relativas à deficiência saíram, assim, da esfera da religião e do misticismo para a ciência, passando a ser perspectivadas não como um atributo divino, mas como um desvio biológico e, nesse sentido, o seu tratamento implicava a reabilitação e a educação. (PESSOTI, 1984, p. 36).

De acordo com um padrão estabelecido como norma, os conceitos de normalidade e de reabilitação estiveram, deste modo, na gênese de medidas e de práticas de integração, a qual partiu do princípio que deveria ser a pessoa portadora de necessidades especiais a modificar-se, segundo os padrões vigentes na sociedade.

Apesar do nítido progresso em relação às atitudes e às práticas de segregação do passado, estas formas de participação social e educativa só responderam em parte aos direitos destas pessoas, na medida em que exigiam pouco da sociedade. Em termos educativos, a investigação a este propósito comprova que:

O comportamento dos alunos com necessidades educativas especiais muda em função das expectativas das pessoas que cuidam deles e, também, quando interagem com pares a quem, por sua vez, vão modificar o comportamento. Os modelos ecológico-sistémicos e transacionais vieram revelar que o desenvolvimento humano só se entende e evolui de forma contextualizada, o que sustenta a fundamentação do modelo inclusivo de educação, na medida em que as crianças aprendem, sobretudo quando se atua sobre o meio ambiente por forma a que encontrem oportunidades de aprendizagem ricas, adultos envolventes e pares estimulantes e organizadores. (BAIRRÃO RUIVO, 2004, 14).

Ao declararmos o ano de 1981 como o Ano Internacional das Pessoas com Deficiência, a Organização das Nações Unidas e a Carta para os Anos 80, proclamada pela Rehabilitation International e recomendada pela Assembleia Geral das Nações Unidas, contribuíram para o aprofundamento das concepções e das práticas relativamente à inclusão social.

Esta Carta de princípios sobre as prioridades internacionais, desenvolvida com base numa ampla consulta a nível internacional relativamente à deficiência, prevenção e reabilitação, definiu, como metas a atingir, a participação total e a igualdade para as pessoas deficientes de todo o mundo, ou seja, o direito de partilhar a vida social normal da sua comunidade, com tudo o que lhe está subjacente.

As Nações Unidas, fundamentada nesta Carta, desenvolveu um Programa Mundial de Ação relativo às Pessoas Deficientes, defendendo que o princípio da igualdade de direitos entre deficientes e não deficientes implica que as necessidades de cada indivíduo tenham igual importância, que essas necessidades deverão constituir a base do planejamento das sociedades e que todos os recursos devem ser empregues de modo a garantir a todo o indivíduo igual oportunidade de participação. As políticas para o deficiente deveriam garantir o seu acesso a todos os serviços comunitários.

A aceitação e a valorização da diversidade, a cooperação entre diferentes e a aprendizagem da multiplicidade são, assim, valores que norteiam a inclusão social, entendida como o processo pelo qual a sociedade se adapta de forma a poder incluir, em todos os seus sistemas, pessoas com necessidades especiais e, em simultâneo, estas se preparam para assumir o seu papel na sociedade. 
O percurso até à inclusão passou por um conjunto de decisões e medidas tomadas no seio de organizações e agências internacionais, como as Nações Unidas e a UNESCO, que tiveram extraordinária importância na introdução progressiva de políticas sociais favoráveis à sua implementação.

Neste sentido, a Declaração Mundial sobre Educação para Todos, realizada em Jomtien, na Tailândia, em 1990, e, em particular, a Conferência Mundial sobre Necessidades Educativas Especiais: Acesso e Qualidade, em 1994, organizada pelo governo de Espanha em cooperação com a UNESCO, que decorreu em Salamanca.

O movimento a favor da inclusão foi fortemente impulsionado pela Declaração de Salamanca, aprovada pelos representantes de vários países e organizações internacionais, em 1994.

Defendendo que a escola regular deve ajustar-se a todas as crianças independentemente das suas condições físicas, sociais, linguísticas ou outras, isto é, crianças portadoras de necessidades especiais, crianças de rua ou crianças que trabalham, crianças de populações imigradas ou nômades, crianças pertencentes a minorias linguísticas, étnicas ou culturais e crianças de áreas ou grupos desfavorecidos ou marginais. (UNESCO, 2015).

Tal documento contribuiu decisivamente para perspectivar a educação de todos os alunos em termos das suas potencialidades e capacidades, para o que, currículos, estratégias pedagógicas e recursos a utilizar adequados, organização escolar facilitadora destas medidas e da cooperação entre docentes e comunidade, são condições fundamentais a considerarmos.

\section{PRINCÍPIO DE IGUALDADE E PROTEÇÃO AO DEFICIENTE}

O princípio da igualdade pressupõe um vínculo a Administração Pública à não discriminação, positiva ou negativa, dos cidadãos, na qual visa a obrigatoriedade em dar tratamento igual a situações que sejam juridicamente iguais, e a obrigação de dar tratamento diferenciado a situações que sejam juridicamente diferentes. Assim, o princípio da igualdade desenvolve-se em duas vertentes: a proibição da discriminação e a obrigação da diferenciação.

Corroborado a este princípio é o da autovinculação da Administração, por seu turno associado ao princípio da imparcialidade, que implica que os seus poderes discricionários devam ser concretizados segundo os mesmos critérios, medidas e condições relativamente a todos os particulares em idêntica situação.

O princípio da igualdade, de que é corolário o princípio da livre e sã concorrência, assume particular relevância na formação dos contratos administrativos no quadro do tratamento relativo aos concorrentes, uma vez que todos têm interesses idênticos; estando em causa a igualdade de oportunidades, assegurada por adequada e atempada publicitação, mas também, a igualdade na aplicação dos critérios de avaliação.

Do ponto de vista aristotélico, nem todos eram considerados cidadãos, uma vez que muitos nem possuíam ou exerciam direitos. Assim, enquanto de um lado era dado aos cidadãos a possibilidade de participação, de outro, os demais eram vistos como seres inferiores que formavam um contingente de escravos e, portanto, não gozavam da possibilidade de ocuparem cargos ou receberem bens do Estado. 
Tal concepção de igualdade sob o olhar de Aristóteles é de que alguns nasceram para o mando e outros para a obediência não se resume apenas a ele. Já, Platão, reconhecia a existência da escravidão onde alguns nasceram para comandar e outros para obedecer.

O filósofo iluminista Jacques Rousseau teceu algumas considerações acerca da igualdade, tanto no seu Discurso sobre a Origem e os Fundamentos da Desigualdade entre os Homens, de 1754, como também no Contrato Social, de 1762, apontando para a existência de uma desigualdade natural ou física decorrente da idade, sexo, constituição do corpo, alma, etc. e, outra, denominada de moral ou política proveniente de certos privilégios de que alguns gozam sobre outros, seja por serem mais abastados ou, ainda, mais poderosos e prestigiados.

Este contrato era estabelecido com base na liberdade de que gozavam os integrantes da sociedade e que, por serem livres, detinham a faculdade de abrir mão de parcela desta em troca da garantia do restante, configurando-se na transposição dos homens do estado de natureza para a formação em sociedade, abrindo mão de parcela da liberdade individualizada em prol do todo, todavia, devendo aos seus membros continuarem com o gozo da maior liberdade tanto quanto possível.

Em linhas gerais, a finalidade do contrato era a conservação plena dos direitos individuais dos cidadãos. Assim, cada um continuava livre e igual. Ao Estado competia eliminar os extremos de pobreza e riqueza, de modo que os homens se tornassem iguais.

Para Rousseau, existiam desigualdades, mas pela convenção do contrato social todos se tornavam perfeitamente iguais.

As desigualdades política e moral tiveram o seu início com o estabelecimento do contrato social, isto é, com a formação dos homens em sociedade. Assim, enquanto de um lado, eram superadas as dificuldades impostas pelo estado de natureza decorrente das diferenças naturais, do outro, iniciava-se uma nova e efetiva desigualdade entre os homens.

É importante aqui rememorar dois pensadores da filosofia política, Pufendorf e Locke, que tiveram influência nas posteriores Declarações de Direitos dos Homens.

Conforme Pufendorf, o fundamento material do direito natural repousa na liberdade, igualdade e sociabilidade dos homens. A liberdade origina-se da dignidade natural e, em razão desta, é igual em todos, fazendo com que, juridicamente, por direito natural, todos os homens sejam iguais. A igualdade de todos é o fundamento do direito natural.

Em contrapartida, para Locke, o indivíduo possui direitos naturais inalienáveis que não podem ser abdicados, em razão de todos os homens serem livres e iguais. A sua teoria foi vista à época como a mais ajustada aos princípios do direito natural e que melhor garantia os direitos do homem.

O princípio de igualdade, também denominado princípio da isonomia, assim como outros, nem sempre será aplicado, podendo ser relativizado de acordo com o caso concreto. Doutrina e jurisprudência já assentam o princípio de que a igualdade jurídica consistindo em assegurar às pessoas de situações iguais os mesmos direitos, prerrogativas e vantagens, com as obrigações correspondentes, o que significa "tratar igualmente os iguais e desigualmente os desiguais na medida em que eles se desigualam", visando sempre o equilíbrio entre todos.

Nota-se, contudo, que a pessoa portadora de necessidades especiais se incluiu como beneficiária de direitos e garantias, e dá mostras do significado do que a doutrina denomina de igualdade material, tal como: tratar os iguais de forma idêntica e os desiguais de forma distinta. A título de exemplos, cite-se o disposto nos artigos $7^{\circ}$, inciso XXXI; 
23, inciso II; 24, inciso XIV; 37, inciso VIII; 203, incisos IV e V; 208, inciso III; 224; 227, $\S 1^{\circ}$, inciso II e $\S 2^{\circ}$; e art. 244, todos da Constituição Federal de 1988.

Segundo os parâmetros do Direito constitucional, podemos discorrer que a Constituição Federal de 1988 adotou o princípio da igualdade de direitos, presumindo aptidões iguais, entendidas estas como uma igualdade de possibilidades virtuais, ou seja, todos os cidadãos têm o direito de tratamento idêntico pela lei, em consonância com os critérios albergados pelo ordenamento jurídico. Assim, o que se proíbe são as diferenciações arbitrárias, as discriminações despropositadas, pois, o tratamento desigual dos casos desiguais, na medida em que se desigualam, faz parte da essência tradicional do próprio conceito de Justiça.

O direito à igualdade da pessoa portadora de necessidades especiais necessita de atendimentos especiais, a fim de assegurar garantias na finalidade de proporcionar a almejada igualdade, ou seja:

\begin{abstract}
A pessoa portadora de deficiência tem direito a um tratamento especial dos serviços de saúde ou à criação de uma escola especial ou, ainda, a um local de trabalho protegido. Todas as situações quebram a igualdade (inicialmente entendida), mas apresentam autorização lógica para tanto. Bom é falar que a legislação precisa vir acompanhada de instrumentos que possam tornar a igualdade um princípio eficaz, sob pena de ser inócua. Em nosso entender, o princípio da não-discriminação é um desdobramento do princípio da igualdade. Percebemos que nosso Legislador Constituinte Originário ressalta, desde o Preâmbulo, a igualdade como valor supremo de uma sociedade fraterna, pluralista e sem preconceitos. No artigo $3^{\circ}$ da $\mathrm{CF} / 88$ vemos os objetivos fundamentais de nossa República, dentre os quais destacamos aqui a promoção do bem de todos, sem preconceitos de origem, raça, sexo, cor, idade e quaisquer outras formas de discriminação. (ARAÚJO, 2011, p. 36-37)
\end{abstract}

Indubitavelmente, quanto à ilegalidade de qualquer forma de discriminação negativa em nosso sistema jurídico. Dray $(1999$, p. 97) diz que "o princípio da nãodiscriminação é uma vertente negativa do princípio da igualdade, surgindo como sua concretização ou reflexo".

A noção de igualdade, como categoria jurídica de primeira grandeza, teve sua emergência como princípio jurídico incontornável nos documentos constitucionais promulgados imediatamente após as revoluções do final do século XVIII. Com efeito, foi a partir das experiências revolucionárias pioneiras dos EUA e da França que se edificou o conceito de igualdade perante a lei, uma construção jurídico-formal segundo a qual a lei, genérica e abstrata, deve ser igual para todos, sem qualquer distinção ou privilégio, devendo o aplicador fazê-la incidir de forma neutra sobre as situações jurídicas concretas e sobre os conflitos interindividuais.

Concebida para o fim específico de abolir os privilégios típicos do ancien régime e para dar cabo às distinções e discriminações baseadas na linhagem, no rang, na rígida e imutável hierarquização social por classes (classement par ordre), essa clássica concepção de igualdade jurídica, meramente formal, firmou-se como ideia-chave do constitucionalismo que floresceu no século XIX e prosseguiu sua trajetória triunfante por boa parte do século XX. 
Os privilégios representavam nesta perspectiva a criação pelo homem de espaços e de zonas delimitadas, susceptíveis de criarem desigualdades artificiais e nessa medida intoleráveis".

Em suma, segundo esse conceito de igualdade que veio a dar sustentação jurídica ao Estado liberal burguês, a lei deve ser igual para todos, sem distinções de qualquer espécie.

O princípio da igualdade perante a lei foi tido, durante muito tempo, como a garantia da concretização da liberdade. Para os pensadores e teóricos da escola liberal, bastaria a simples inclusão da igualdade no rol dos direitos fundamentais para se ter esta como efetivamente assegurada no sistema constitucional. Contudo, paulatinamente sustentando por Dray (1999, p. 55):

A concepção de uma igualdade puramente formal, assente no princípio geral da igualdade perante a lei, começou a ser questionada, quando se constatou que a igualdade de direitos não era, por si só, suficiente para tornar acessível a quem fosse socialmente desfavorecido, as oportunidades de que gozavam os indivíduos socialmente privilegiados. Importaria, pois, colocar os primeiros ao mesmo nível de partida. Em vez de igualdade de oportunidades, importava falar em igualdade de condições.

Portanto, imperiosamente seria a adoção de uma concepção substancial da igualdade, que levasse em conta em sua operacionalização não apenas certas condições fáticas e econômicas, mas também certos comportamentos inevitáveis da convivência humana, como é o caso da discriminação.

Da transição da ultrapassada noção de igualdade "estática" ou "formal" ao novo conceito de igualdade "substancial" surge a ideia de "igualdade de oportunidades", noção justificadora de diversos experimentos constitucionais pautados na necessidade de se extinguir ou de pelo menos mitigar o peso das desigualdades econômicas e sociais e, consequentemente, promover a justiça social.

A partir dessa perspectiva resultou o surgimento, em diversos ordenamentos jurídicos nacionais e na esfera do Direito Internacional dos Direitos Humanos, políticas sociais de apoio e de promoção de determinados grupos socialmente fragilizados. Ressaltando que a concepção liberal de igualdade que capta o ser humano em sua conformação abstrata, genérica, o Direito passa a percebê-lo e a tratá-lo em sua especificidade, como ser dotado de características singularizantes. Para Piovesan (1998, p. 130):

Do ente abstrato, genérico, destituído de cor, sexo, idade, classe social, dentre outros critérios, emerge o sujeito de direito concreto, historicamente situado, com especificidades e particularidades. Daí apontar-se não mais ao indivíduo genérica e abstratamente considerado, mas ao indivíduo especificado, considerando-se categorizações relativas ao gênero, idade, etnia, raça, etc.

A consagração normativa dessas políticas sociais representa, pois, um momento de ruptura na evolução do Estado moderno. Com efeito, assinala a Professora Carmen Lúcia Antunes Rocha, em nenhum Estado Democrático, até a década de 60, e quase até esta última década do século XX cuidou-se em promover a igualação e vencerem-se os 
preconceitos por comportamentos estatais e particulares obrigatórios pelos quais se superassem todas as formas de desigualdade injusta.

\section{CONCLUSÃO}

Conclui-se que a compreensão da pessoa portadora de necessidades especiais é um importante fator de desigualdade, é ainda, portanto, um desafio para as políticas sociais brasileiras, no que diz respeito a assistência.

Trata-se de uma das políticas mais importantes de transferência de renda no país e em toda América Latina, sendo uma política de vanguarda, na qual reconhece que o tema do bem-estar para os deficientes é uma questão de justiça social e de políticas distributivas de renda.

O reconhecimento da política como um benefício individual exigirá uma revisão dos critérios periciais de forma a permitir a inclusão de uma maior variedade de expressões e intensidades da deficiência e não apenas as deficiências extremamente graves.

O Direito Internacional dos Direitos Humanos resta efetivamente consolidar como disciplina jurídica autônoma, universalmente reconhecida, encontrando-se em progressiva expansão e aperfeiçoamento, sempre em busca permanente de promover e proteger a dignidade da pessoa humana e os direitos humanos, no âmbito mundial.

Tal reconhecimento como expressão da diversidade humana é recente e ainda um desafio para as sociedades democráticas e para as políticas públicas, mas cabe a estes órgãos públicos sancionarem e promulgarem leis visando o benefício dessas pessoas que necessitam de atendimentos especiais e acima de tudo respeito e integridade.

A Convenção sobre os Direitos das Pessoas com Deficiência da Organização das Nações Unidas age como um divisor de águas nesse movimento, pois instituiu um novo marco de compreensão da deficiência (ONU, 2006), assegurando a vida digna não só em resumo à oferta de bens e serviços médicos, mas exigindo também a eliminação de barreiras e a garantia de um ambiente social acessível aos corpos com impedimentos físicos, intelectuais ou sensoriais.

A desvantagem social vivenciada pelas pessoas portadoras de necessidades especiais não é uma sentença da natureza, mas o resultado de um movimento discursivo da cultura da normalidade, que descreve os impedimentos corporais como abjetos à vida social. O modelo social da deficiência desafiou as narrativas do infortúnio, da tragédia pessoal e do drama familiar que confinaram o corpo com impedimentos ao espaço doméstico do segredo e da culpa.

Assim, as propostas de igualdade do modelo social não apenas propuseram um novo conceito de deficiência em diálogo com as teorias sobre desigualdade e opressão, mas também revolucionaram a forma de identificação do corpo com impedimentos e sua relação com as sociedades.

A adoção da Convenção dos Direitos das Pessoas com Deficiência reconhece a questão da deficiência como um tema de justiça, direitos humanos e promoção da igualdade. Sobretudo, a Convenção foi ratificada em 2008, na qual exige a revisão das legislações infraconstitucionais e o estabelecimento de novas bases para a formulação das políticas públicas destinadas à população portadora de necessidades especiais. Uma das exigências da Convenção é a revisão imediata do conjunto de leis e ações do Estado referentes à população portadora de necessidades especiais. 
A despeito, o cumprimento dessa medida somente trará resultados diretos para a garantia do bem-estar, a promoção da dignidade e integridade dessas pessoas portadoras de necessidades especiais, fazendo com sejam encarados como cidadãos 'normais' e não como figuras estigmatizadas pelo preconceito.

\section{REFERÊNCIAS BIBLIOGRÁFICAS}

ARAÚJO, Luiz Aberto David. Barrados pessoa com deficiência sem acessibilidade: como cobrar, o que cobrar e de quem cobrar. 1.ed. Petrópolis: KBR, 2011.

BAIRRÃO RUIVO, Joaquim. Prefácio. In. PEREIRA, Filomena. Políticas e práticas educativas: o caso da educação especial e do apoio sócio-educativo nos anos 2002 a 2004. Lisboa: Fundação Liga Portuguesa dos Deficientes Motores, 2004.

BARNES, Colin; OLIVER, Mike; BARTON, Len. Disability studies today. Cambridge: The Polity Press, 2002.

CONDE, Fernando Jiménez. Tutela jurisdicional de los derechos fundamentales. Murcia: DM Librero-Editor. 2002.

CORKER, Mairiam; SHAKESPEARE, Tom. Disability, postmodernity, embodying disability theory. Londres: Continuum, 2002.

CORREIA, Luís de Miranda. Alunos com Necessidades Educativas Especiais nas Classes Regulares. Porto: Porto Editora, 1997.

DINIZ, Debora. O que é deficiência. São Paulo: Editora Brasiliense, 2007.

DRAY, Guilherme Machado. O princípio da igualdade no direito do trabalho. Coimbra: Livraria Almedina, 1999.

FOUCAULT, Michel. O nascimento da clínica. São Paulo: Editora Forense, 2004.

IBGE - Instituto Brasileiro de Geografia e Estatística. Censo demográfico de 2000. Disponível em: <http://www.ibge.gov.br>. Acesso: 05 out. 2015.

KITTAY, Eva. Love's labor: essays on women, equality and dependency. New York: Routledge, 1998.

LANE, Harlan. Construction of deafness. In: DAVIS, Lennard. The disability studies reader. New York: Routledge, 1997.

MAZZOTTA, Marcos José da Silveira. Educação Escolar Comum ou Especial? São Paulo: Livraria Pioneira Editora, 1986.

NUSSBAUM, Martha. Las fronteras de la justicia: consideraciones sobre la exclusión. Barcelona: Paidos Iberica Ediciones, 2007.

ONU - Organização das Nações Unidas. Convenção sobre os Direitos das Pessoas com Deficiência. Doc. A/61/611, New York, 2006.

PESSOTI, Isaias. Deficiência Mental: da superstição à ciência. São Paulo: EDUSP, 1984.

PIOVESAN, Flávia. Direitos humanos. Curitiba: Juruá, 2006.

SHAKESPEARE, Tom. Disability rights and wrongs. New York: Routledge, 2006.

UNESCO. Declaração Mundial sobre Educação para Todos: satisfação das necessidades básicas de aprendizagem. Disponível em: <http://unesdoc.unesco.org/ images/0008/000862/ 086291por.pdf>. Acesso em: 15 out. 2015.

Recebido em: 11 de fevereiro de 2016.

Aprovado em: 08 de maio de 2016. 